\title{
A CLINICO-MICROBIOLOGICAL STUDY OF OSTEOMYELITIS IN A TERTIARY CARE HOSPITAL IN KARNATAKA
}

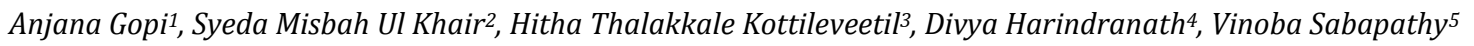 \\ 1 Professor, Department of Microbiology, KIMS, Bangalore. \\ ${ }^{2} 3^{\text {rd }}$ Year Junior Resident, Department of Microbiology, KIMS, Bangalore. \\ ${ }^{3} 3^{\text {rd }}$ Year Junior Resident, Department of Microbiology, KIMS, Bangalore. \\ ${ }^{4} 3^{\text {rd }}$ Year Junior Resident, Department of Microbiology, KIMS, Bangalore. \\ $53^{\text {rd }}$ Year Junior Resident, Department of Microbiology, KIMS, Bangalore.
}

\section{ABSTRACT}

\section{BACKGROUND}

Bone and joint infections are painful for patients and frustrating for both doctors and patients. Osteomyelitis presents a variety of challenges to the physician. The severity of the disease is staged depending upon the infection's particular features, including its aetiology, pathogenesis, extent of bone involvement, duration, and host factors. The high success rates of antimicrobial therapy in most infectious diseases have not yet been achieved in bone and joint infections.

\section{AIM}

To determine the microbiological profile and antibiotic susceptibility patterns of organisms isolated from cases of osteomyelitis.

\section{METHODS}

Pus samples were collected for bacterial culture from 90 cases of osteomyelitis between June 2013 and August 2015 and processed in the laboratory.

\section{RESULTS}

Among the 90 patients studied, most of them were men (79), with median age group 30-50 years, affected by chronic osteomyelitis (77\%) or acute osteomyelitis (22\%), with predominant involvement of lower limbs (90.5\%). A total of 70 isolates of bacteria were obtained from 90 clinical samples. The most frequently isolated pathogens were Staphylococcus aureus (51.4\%), Klebsiella pneumoniae (11.4\%), Enterococcus faecalis (8.5\%), Pseudomonas aeruginosa and Proteus mirabilis (7\%). Susceptibility of gram positive organisms to linezolid, tetracycline, vancomycin and gentamicin was $100 \%$.

Gram negative organisms are highly susceptible to aminoglycosides, levofloxacin, piperacillin and tazobactam (87.5\%). Four methicillin resistant Staphylococcus aureus were isolated.

\section{CONCLUSION}

Osteomyelitis remains a serious therapeutic challenge, especially when associated with gram negative bacteria. We emphasize the need to consider these agents in diagnosed cases of osteomyelitis, so that an ideal antimicrobial treatment can be administered since the very beginning of the therapy.

\section{KEYWORDS}

Osteomyelitis, Bones, Antibiotics, Staphylococcus Aureus.

HOW TO CITE THIS ARTICLE: Gopi A, Khair SMU, Kottileveetil HT, et al. A clinico-microbiological study of osteomyelitis in a tertiary care hospital in Karnataka. J Evolution Med Dent Sci 2016;5(1):15-18, DOI: 10.14260/jemds/2016/4

\section{INTRODUCTION}

Osteomyelitis is an inflammatory process caused by an infecting micro-organism often accompanied by bone destruction. ${ }^{1}$ It is a disease of antiquity and is one of the infectious diseases that is most difficult to treat. ${ }^{2}$ Its first descriptions go back to the Hippocrates era.

The infection can be limited to a single portion of the bone or can involve several regions, such as marrow, cortex, periosteum and the surrounding soft tissue. Osteomyelitis develops from haematogenous spread of an infectious agents, invasion of bone tissue from adjacent site of infection, breakdown of tissue by trauma or surgery. ${ }^{3}$

Financial or Other, Competing Interest: None.

Submission 14-12-2015, Peer Review 15-12-2015,

Acceptance 30-12-2015, Published 01-01-2016.

Corresponding Author:

Dr. Syeda Misbah Ul Khair,

Junior Resident,

Department of Microbiology,

V. V. Puram, KIMS, Bangalore

E-mail:drmisbahsr@gmail.com

DOI:10.14260/jemds/2016/4
When established, bacteria produce a local inflammatory reaction that promotes bone necrosis and the formation of sequestra. ${ }^{2}$ Acute osteomyelitis evolves over several days or weeks. Whereas chronic osteomyelitis, which is somewhat arbitrarily defined as long-standing infection that evolves over months or even years, characterised by the persistence of microorganisms, low-grade inflammation, and the presence of dead bone (Sequestrum), fistulous tracts and new bone formation identified radiologically. ${ }^{2,4}$

The overall prevalence of osteomyelitis is 5 to $6 \%$. Tibia is the most common site of open fracture and infection. ${ }^{4}$

The most important risk factors of osteomyelitis are trauma (Primarily open fractures and severe soft tissues injury), vascular insufficiency, diabetes, obesity, surgical wound infection, mismanagement of acute osteomyelitis, haemoglobinopathies such as sickle cell diseases and the age group with the highest risk involving children and elderly. ${ }^{5}$

A single pathogenic organism is almost always recovered from the bone in haematogenous osteomyelitis, whereas in contiguous infection it is usually polymicrobial. ${ }^{2}$ 
In adults, Staphylococcus aureus is the most common organism isolated (50\%-75\%); other organisms isolated are coagulase negative Staphylococci, Pseudomonas, Proteus, Escherichia coli and Enterococci. ${ }^{6}$

Removal of dead bone is the gold standard of treatment. Osteomyelitis is rarely controlled without the combination of careful, complete, surgical debridement and prolonged 4 to 6 weeks parenteral antibiotic therapy at high dose.4,7

The antimicrobial agent of choice depends on the type of organism isolated, their antimicrobial susceptibility, pharmacokinetic factors like bone penetration, vascularity of the affected area, presence of any prosthetic material and the patient tolerance to the first line antibiotic. ${ }^{4}$

With the emergence of mixed infections caused by gram negative bacteria secreting beta-lactamases including Extended Spectrum Beta- Lactamases (ESBL), AmpC betalactamases and Metallo-Beta-Lactamase (MBL), as a cause of antimicrobial resistance, has led to difficulties in the treatment and eradication of infection. ${ }^{5}$

Sustained eradication of chronic osteomyelitis is difficult to achieve for several reasons, including the low levels of most antibiotic agents in chronically infected bone; the decreased metabolism of the pathogens, which are usually incorporated into a relatively impermeable glycocalyx biofilm; and the particular characteristics of the osseous environment as regards $\mathrm{pH}$ level, partial pressure of oxygen and protein concentrations. ${ }^{8}$

Proper management of osteomyelitis requires accurate microbial isolation and appropriate antibiotic administration. Hence, the present study was conducted to determine the bacterial agents causing osteomyelitis and their antibiogram.

\section{MATERIALS AND METHODS}

For this prospective study, we included all patients with a diagnosis of osteomyelitis who were treated at a tertiary health care centre in Karnataka from June 2013 to August 2015. Pus samples were collected for bacterial culture from 90 cases of osteomyelitis. Only the first positive culture for each identified patient was considered. Symptoms of infection at presentation were divided into four groups: local pain, hyperaemia, sinus tract formation or a radiograph showing signs of osteomyelitis.

We classified osteomyelitis as acute or chronic, according to the onset of symptoms.

Culture samples- All pus samples were collected in the surgical unit after extensive debridement. If it was a sinus or ulcer, swab samples were obtained after brief cleansing of the ulcer with sterile physiologic saline by means of a sterile compress passed over the ulcer surface to reduce the amount of contaminating bacteria. Swab samples were obtained from the bottom of the ulcer by vigorous rotation of the swab.

Samples were sent to the microbiology laboratory immediately. Samples were processed as per routine laboratory procedures and causative agents were isolated and identified. Susceptibility tests were performed in all cases using the Kirby Bauer method of disc diffusion and reported in accordance with the CLSI criteria in force at that time.

\section{RESULTS}

From June 2013 to August 2015, a total of 90 patients diagnosed with osteomyelitis were included in the study and pus culture and sensitivity were performed.
Of whom 10 patients had associated diabetes mellitus; 5 cases were associated with prosthetic device infection.

Twenty cases were diagnosed as acute osteomyelitis and 70 were chronic. Predominant involvement of lower limbs was noticed with tibia and femur accounting for $32 \%$ and $27 \%$ respectively (Figure-1).

Among 90 patients, 79 patients were male and 11 were female. Male-to-female ratio=7.1:1 (Table -1).

\begin{tabular}{|c|c|c|c|c|c|c|}
\hline $\begin{array}{c}<10 \\
\text { yrs. }\end{array}$ & $\begin{array}{c}11-20 \\
\text { yrs. }\end{array}$ & $\begin{array}{c}\mathbf{2 1 - 3 0} \\
\text { yrs. }\end{array}$ & $\begin{array}{c}\mathbf{3 1 - 4 0} \\
\text { yrs. }\end{array}$ & $\begin{array}{c}\mathbf{4 1 - 5 0} \\
\text { yrs. }\end{array}$ & $\begin{array}{c}\mathbf{5 1 - 6 0} \\
\text { yrs. }\end{array}$ & $\begin{array}{c}>\mathbf{6 0} \\
\text { yrs. }\end{array}$ \\
\hline 6 & 13 & 9 & 20 & 21 & 8 & 13 \\
\hline \multicolumn{7}{|c|}{ Table1: Age Distribution of the Patients } \\
\hline
\end{tabular}

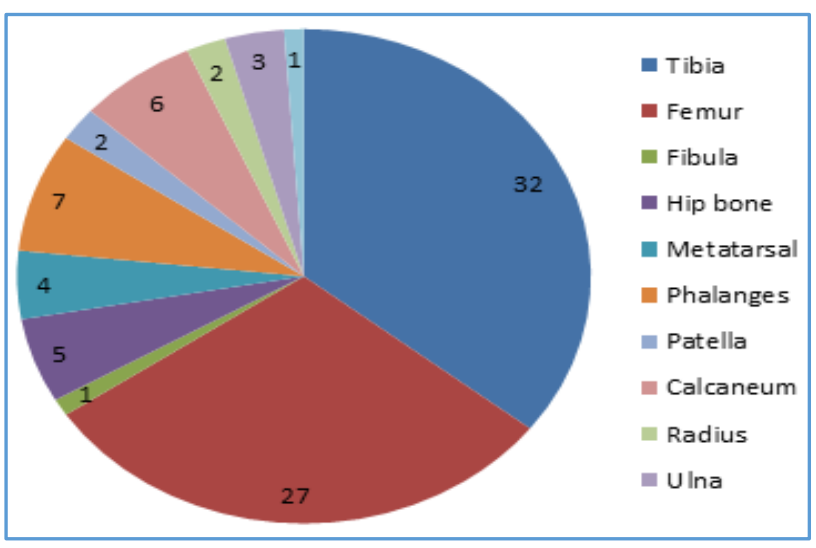

Fig. 1: Distribution of the Bones Affected

\section{Microbiology}

Out of the 90 pus culture samples processed 66 samples were culture positive and rest of the samples showed no growth. $6.1 \%$ of the case showed polymicrobial growth and the rest had monomicrobial growth (Table-2).

Staphylococcus aureus was the most common isolate (51\%) followed by Klebsiella pneumoniae (11\%) (Figure-2).

For polymicrobial growth, the pattern of organisms isolated was as follows:

- Staphylococcus aureus + Escherichia coli.

- Staphylococcus aureus + Proteus mirabilis.

- Enterococcus faecalis+ Klebsiella pneumoniae.

- Pseudomonas aeruginosa + Escherichia coli.

\begin{tabular}{|c|c|c|c|}
\hline Type of Growth & $\begin{array}{c}\text { Number of } \\
\text { Samples }\end{array}$ & $\mathbf{\%}$ & $\begin{array}{c}\text { Number of } \\
\text { Isolates }\end{array}$ \\
\hline Monomicrobial & 62 & $93.9 \%$ & 62 \\
\hline Polymicrobial & 4 & $6.1 \%$ & 8 \\
\hline Total & $\mathbf{6 6}$ & $\mathbf{1 0 0}$ & $\mathbf{7 0}$ \\
\hline \multicolumn{4}{|c|}{ Table 2: Profile of Infections } \\
\hline
\end{tabular}

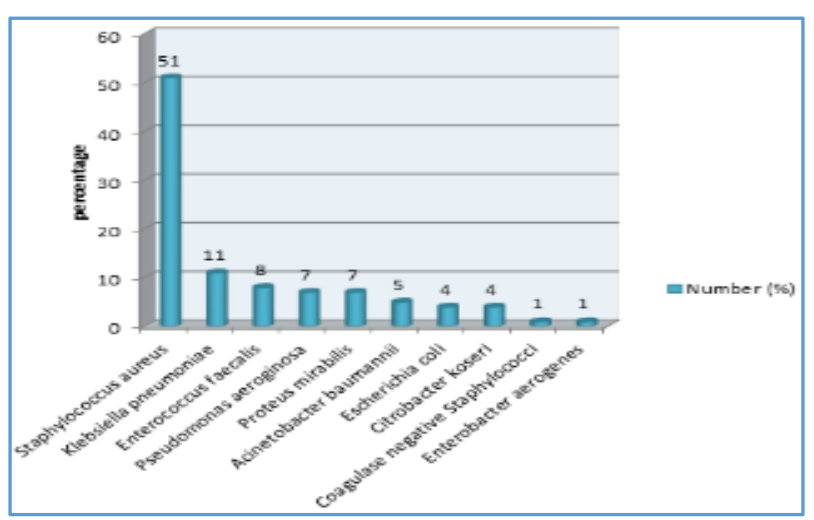

Fig. 2: Distribution of Organisms Isolated in our study 


\section{Antibiotic Susceptibility of the Isolates}

Among the total 43 gram positive isolates, 36 were Staphylococcus aureus, 6 were Enterococcus faecalis, 1 was coagulase negative Staphylococci. The gram positive organisms isolated were $100 \%$ sensitive to drugs like linezolid, tetracycline, vancomycin and gentamicin (Table-3).

Among the total 36 isolates of Staphylococcus aureus. 32 were sensitive to cloxacillin.4 isolates were methicillin resistant. The lowest sensitivity was shown to amoxyclav (61\%).
The total number of gram negative bacilli isolated was 27 (as described above). Most common isolate among them was Klebsiella pneumoniae. It showed high sensitivity to amikacin, levofloxacin and gentamicin (87.5\%). They showed lowest sensitivity to cephalosporins (12.5\%) and were $100 \%$ resistant to penicillins (Table-4).

Pseudomonas aeruginosa showed $100 \%$ susceptibility to aminoglycosides, piperacillin tazobactam, meropenem and levofloxacin. High resistance was seen towards amoxicillinclavulanic acid and cephalosporins (80\%).

\begin{tabular}{|c|c|c|c|c|c|c|c|c|c|c|c|c|}
\hline & $\begin{array}{c}\text { Amoxy } \\
\text { clav }\end{array}$ & $\begin{array}{c}\text { Ciproflox } \\
\text { acin }\end{array}$ & $\begin{array}{c}\text { Cefepi } \\
\text { me }\end{array}$ & $\begin{array}{c}\text { Cefper } \\
\text { azone }\end{array}$ & $\begin{array}{c}\text { Cotrimax } \\
\text { azole }\end{array}$ & $\begin{array}{c}\text { Cloxaci } \\
\text { llin }\end{array}$ & $\begin{array}{l}\text { Clinda } \\
\text { mycin }\end{array}$ & $\begin{array}{c}\text { Erythrom } \\
\text { ycin }\end{array}$ & $\begin{array}{c}\text { Linezol } \\
\text { id }\end{array}$ & $\begin{array}{c}\text { Tetrac } \\
\text { yclin }\end{array}$ & $\begin{array}{l}\text { Vanco } \\
\text { mycin }\end{array}$ & Gentamicin \\
\hline S. Aureus & 61 & 90 & 88 & 88 & 80 & 88 & 94 & 80 & 100 & 100 & 100 & 100 \\
\hline $\begin{array}{c}\text { Enterococ } \\
\text { cus }\end{array}$ & 83 & 100 & 83 & 83 & 83 & 83 & 100 & 83 & 100 & 100 & 100 & 100 \\
\hline CONS & 100 & 100 & 100 & 100 & 100 & 100 & 100 & 100 & 100 & 100 & 100 & 100 \\
\hline
\end{tabular}

\begin{tabular}{|c|c|c|c|c|c|c|c|c|c|c|c|c|}
\hline & $\begin{array}{c}\text { Ampic } \\
\text { illin }\end{array}$ & $\begin{array}{c}\text { Amoxy } \\
\text { clav }\end{array}$ & $\begin{array}{c}\text { Amik } \\
\text { acin }\end{array}$ & $\begin{array}{c}\text { Ciproflo } \\
\text { xacin }\end{array}$ & $\begin{array}{c}\text { Cefep } \\
\text { ime }\end{array}$ & $\begin{array}{c}\text { Cefpera } \\
\text { zone }\end{array}$ & $\begin{array}{c}\begin{array}{c}\text { Cefuro } \\
\text { xime }\end{array} \\
\end{array}$ & $\begin{array}{c}\text { Cotrimax } \\
\text { azole }\end{array}$ & $\begin{array}{c}\begin{array}{c}\text { Imipe } \\
\text { nem }\end{array} \\
\text { nat }\end{array}$ & $\begin{array}{c}\begin{array}{c}\text { Levoflo } \\
\text { xacin }\end{array} \\
\end{array}$ & $\begin{array}{c}\begin{array}{c}\text { Pipercillin+taz } \\
\text { obactum }\end{array} \\
\end{array}$ & $\begin{array}{l}\text { Genta } \\
\text { micin }\end{array}$ \\
\hline $\begin{array}{c}\text { Klebsiella } \\
\text { pneumoniae }(\mathrm{n}=8)\end{array}$ & $\circ$ & o & 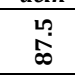 & m & $\hat{m}$ & $\stackrel{\text { L }}{\mathrm{N}}$ & นกำ & in & นุ & $\begin{array}{c}\substack{n \\
\infty} \\
\infty\end{array}$ & n & $\stackrel{\substack{n \\
\infty}}{\stackrel{\infty}{\infty}}$ \\
\hline E. coli $(\mathrm{n}=3)$ & 0 & 0 & $\stackrel{7}{0}$ & ๑ & : & 8 & $\stackrel{8}{8}$ & 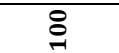 & $\stackrel{7}{0}$ & $\stackrel{7}{0}$ & $\stackrel{7}{0}$ & $\stackrel{1}{0}$ \\
\hline $\begin{array}{c}\begin{array}{c}\text { Acinetobacter } \\
\text { baumannii }(\mathrm{n}=4)\end{array}\end{array}$ & $\stackrel{\text { N }}{ }$ & $\stackrel{L}{N}$ & in & $\stackrel{h}{N}$ & in & $\stackrel{\text { ㄴ }}{2}$ & $\stackrel{L}{N}$ & $\stackrel{L}{N}$ & $\stackrel{\mathfrak{N}}{\circ}$ & 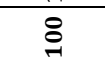 & 옹 & in \\
\hline $\begin{array}{c}\text { Proteus mirabilis } \\
\quad(\mathrm{n}=5)\end{array}$ & q & $q$ & $\stackrel{7}{\circ}$ & 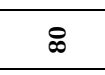 & $\stackrel{7}{\circ}$ & 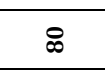 & 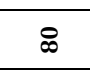 & $q$ & 8 & $\stackrel{7}{\circ}$ & $\stackrel{1}{\circ}$ & 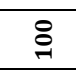 \\
\hline $\begin{array}{c}\text { Citrobacter koseri } \\
(\mathrm{n}=1)\end{array}$ & 0 & 0 & $\stackrel{7}{\circ}$ & $\stackrel{7}{\circ}$ & $\stackrel{7}{\circ}$ & $\stackrel{7}{\circ}$ & $\stackrel{7}{\circ}$ & $\stackrel{7}{\circ}$ & $\stackrel{7}{\circ}$ & $\stackrel{7}{\circ}$ & $\stackrel{7}{\circ}$ & 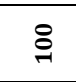 \\
\hline $\begin{array}{c}\text { Enterobacter } \\
\text { aerogenes }(\mathrm{n}=1)\end{array}$ & 0 & 0 & 0 & 0 & 0 & 0 & 0 & 0 & $\stackrel{7}{\circ}$ & $\stackrel{7}{\circ}$ & $\stackrel{一}{0}$ & 0 \\
\hline
\end{tabular}

\section{DISCUSSION}

Osteomyelitis, characterised by infected dead bone and in most cases poor local vascularisation within a compromised soft-tissue envelope, is difficult to eradicate especially if it is a chronic case. Long term antibiotic therapy is required for months to years. This situation makes the accurate identification of the pathogen an absolute cornerstone of antimicrobial therapy.

Widespread use of antibiotics has altered aetiological pattern of infections and antibiotic susceptibility. Hence continuous monitoring of susceptibility pattern needs to be carried out in individual setting so as to detect the true burden of antibiotic resistance among organisms and prevent their further emergence by judicious use of drugs.

In our study, osteomyelitis was predominantly seen in males than females, which correlates with study conducted by Mita et al. ${ }^{5}$ in Mysore, Karnataka and also with a study conducted by Zuluaga and Galvis et al. ${ }^{9}$ in patients with chronic osteomyelitis.

Our study showed the predominant age group involved was between 11-50 years, which correlates with studies conducted by Mita et al. ${ }^{5}$ and Carvahlo et al. ${ }^{10}$

The most common site involved was tibia (35.5\%) and femur (30\%) which is consistent with Mita et al..$^{5}$ and Zuluaga et al. ${ }^{9}$ Collection of specimen before the administration of antibiotics, use of proper transport medium and other factors play a role in incidence of positive culture. Monomicrobial flora was seen in $93.9 \%$, polymicrobial flora in $6.1 \%$.

The causative agent is often associated with mode of infection and age of the patient. Our study showed the most common causative agent was Staphylococcus aureus (51\%), which is consistent with studies conducted by Saurabh Agarwal et al. ${ }^{11}$ and Gulati et al. ${ }^{12}$

Our study showed 4 isolates (5\%) of Methicillin-resistant Staphylococcus aureus among total 70 isolates which is lower incidence compared to the studies by Senneville et al. (11\%). ${ }^{8}$ and Mita et al. (40\%). ${ }^{5}$

Staphylococcus aureus is by far the most commonly involved because organism elaborates a range of extracellular and cell-associated factors contributing to its virulence. S. aureus expresses several adhesions (MSCRAMM, microbial surface components recognising adhesive matrix molecules) on its surface which helps in colonisation. The second set of factors (Protein A, some toxins, capsular polysaccharides) promote evasion from host defences. Its ability to invade the tissues and formation of biofilms explain the persistent bone infection cause by this organism. ${ }^{1}$

Among other organisms isolated are Klebsiella pneumoniae, Enterococcus faecalis ,Pseudomonas aeroginosa, Acinetobacter baumannii, Proteus mirabilis, Citrobacter koseri, Enterobacter aerogenes and coagulase negative Staphylococci, which is consistent with studies conducted by Mita et al. ${ }^{5}$ and Ali et al. ${ }^{4}$

Although gram-negative bacilli represent a minor portion of all the pathological agents isolated in osteomyelitis cases, they are of major clinical importance due to the peculiarities of their antimicrobials susceptibility pattern and due to the co-morbidities generally affecting those patients. ${ }^{10}$ Enteric gram negative bacilli are amongst the common causative agents as many orthopaedic patients are bedridden for prolonged periods. 
Contamination of wounds, dressing, linen, clothes and even hands during perineal hygiene plays a major role in increasing chances of transmission of infection. ${ }^{13}$

Pseudomonas and Non-fermenting gram negative bacilli causing infections have been reported to be causative agents of acute postoperative osteomyelitis seen secondary to open fractures in military personnel.10 and also in amputation stumps. Our study has recorded about 5-7\% incidence of infection by these organisms. This can be explained as Pseudomonas can multiply on common objects in a hospital environment like soaking buckets, plaster of Paris etc., has higher chances of spread. ${ }^{13}$

In most patients with osteomyelitis, early antibiotic therapy produces the best results. Initial treatment with IV beta -lactams is suggested along with fluoroquinolones. In case of mixed infections, use of amoxicillin-clavulanic acid, piperacillin- tazobactam and meropenem is suggested. ${ }^{14}$

Our study has recorded high susceptibility of gram positive organisms to fluoroquinolones, linezolid, tetracycline, vancomycin and gentamicin and least sensitivity to betalactams, whereas gram negative organisms show good susceptibility to piperacillin-tazobactam and imipenem. The bacteria are resistant to amoxyclav and cephalosporins because of their routine use. Hence, use of other classes of antibiotics is advised for the treatment.

The advent of prosthetic joints has added new dimensions to the challenges of septic arthritis and osteomyelitis, as these are prone to become infected by a wide range of organisms including low grade pathogens. The risk of infection is highest during the first 2 years after implantation but persists at lower levels as long as the prosthesis remains in place. ${ }^{1}$

Our study recorded 5 cases of osteomyelitis associated with prosthetic devices. E. coli was the most common isolate among these cases. Treatment with parenteral antibiotics is advised with removal of implant.14

\section{CONCLUSION}

Osteomyelitis is continuous to be a therapeutic challenge. Identification of causative organism and performance of antibiotic susceptibility studies are critical in the selection of antimicrobial agents. Multidrug resistance is on the rise, hence appropriate culture and susceptibility reports and treatment accordingly will prevent development of drug resistance and indiscriminate use of antibiotics.

\section{REFERENCES}

1. Lew DP, Waldvogel FA. Osteomyelitis. Lancet 2004;364:369-79.

2. Mandell GL, Bennett JE, Dolin R Mandells. Douglas and Benett's principles and practice of infectious diseases, $6^{\text {th }}$ edition, Philadelphia, Elsevier Churchill Livingstone, 2005;1:1322-1330.

3. Forbes BA, Sahm DF, et al. Bailey and Scott's diagnostic microbiology, $12^{\text {th }}$ edition, China, Mosby Elsevier, 2007;908-913.

4. Ali M, Radha Kumari. Evaluation of bacteriological profile of chronic osteomyelitis in a Tertiary Care Hospital. International Journal of Scientific Research. Nov 2014;3:11.

5. Wadekar MD, Anuradha K. Chronic Osteomyelitis: Aetiology and antibiotic susceptibility pattern. International Journal of recent trends in Science and Technology 2014;9(3):337-340.

6. Calhoun JH, Manring MM. Osteomyelitis of long bones. Seminars in plastic surgery 2009;23:2.

7. Wispling Hoff $\mathrm{H}$, Bischoff $\mathrm{T}$, Tallent SM, et al. Nosocomial bloodstream infections in US hospitals: analysis of 24,179 cases from a prospective nationwide surveillance study. Clin Infect Dis 2004;39:309-17.

8. Eric Senneville, Hugues Melliez. Culture of percutaneous bone biopsy specimens for diagnosis of diabetic foot osteomyelitis: concordance with ulcer swab cultures. Clinical Infectious Diseases 2006;42:57-62.

9. Zuluaga FA, Galvis W, Saldarriaga JG, et al. Etiologic diagnosis of chronic osteomyelitis: a prospective study. Arch Intern Med 2006;166(1):95-100.

10. Vladimir Cordeiro de Carvalho Priscila Rosalba Domingos de Oliveira, Karine Dal-Paz, Adriana Pereira de Paula, et al. Gram-negative osteomyelitis: clinical and microbiological profile. BRAZ J INFECT DIS 2012;16(1):63-67.

11. Agarwal S, Zahid Mohd, Mohd KA Sherwani, et al. Comparison of the results of sinus track culture and sequestrum culture in chronic osteomyelitis. Acta Orthopaedica Belgica 2005; Vol. 71-2: 209-212.

12. Kaur J, Gulati VL, Aggarwal A, et al. Bacteriological profile of osteomyelitis with special reference to Staphylococcus aureus. Indian Journal for the Practising Doctor 2008;4:6.

13. Agrawal C Alok, Jain Shuddhatma, Jain RK, et al. Pathogenic bacteria in an orthopaedic hospital in India. J Infect Developing Countries 2008;2(2):120-123.

14. Zimmereli W. Osteomyelitis. Harrison's textbook of Internal Medicine 19th edition; 158:838-845. 